\title{
Stress related to care: the impact of childhood cancer on the lives of parents ${ }^{1}$
}

\author{
Daniela Fernanda dos Santos Alves ${ }^{2}$ \\ Edinêis de Brito Guirardello ${ }^{3}$ \\ Andréa Yamaguchi Kurashima ${ }^{4}$
}

Objectives: The objective was to assess the stress levels of parents of children with cancer and to identify correlations among demographic data and anxiety levels. Methods: A descriptive, crosssectional study, conducted in two Brazilian institutions, with 101 parents of children with cancer. Through interviews, parents responded to two instruments: Pediatric Inventory for Parents - Brazilian version, which assesses stress levels, and State-Trait Anxiety Inventory, for the measurement of anxiety. The correlations between the instruments and the sociodemographic variables of the parents and children were evaluated using the Spearman correlation coefficient. Results: Higher levels of stress and anxiety were seen by young parents, young children and with less time since diagnosis. The fear of death and the disease impact on the life of a child were the events considered the most stressful for the parents. Conclusions: In clinical practice, the nurse who can identify the occurrence of these symptoms becomes capable of planning nursing care that includes the family in decisions about the care. Moreover, she can provide support to help parents manage their stress levels and positively face the illness of their children.

Descriptors: Neoplasms; Child; Parents; Pediatric Nursing.

\footnotetext{
${ }^{1}$ Paper extracted from master's thesis "Adaptação e validação do instrumento Pediatric Inventory for Parents - PIP para a cultura brasileira" presented to Universidade Estadual de Campinas, Campinas, SP, Brazil.

2 Doctoral student, Faculdade de Enfermagem, Universidade Estadual de Campinas, Brasil. Enfermeira, Hospital de Clínicas, Universidade Estadual de Campinas, Campinas, SP, Brazil.

${ }^{3} \mathrm{PhD}$, Associate Professor, Faculdade de Enfermagem, Universidade Estadual de Campinas, Campinas, SP, Brazil.

${ }^{4}$ PhD, RN, Fundação Antônio Prudente, São Paulo, SP, Brazil.
} 


\section{Introduction}

Childhood cancer accounts for about 3\% of the tumors in the majority of the populations, and their high survival rate guarantees the status of potentially curable disease $^{(1)}$. However, pediatric cancer is still a disease that causes suffering, pain and the loss of family structure(2). The family, primarily responsible for the care and wellbeing of the child, also has to watch over the physical, emotional and social well-being of its other members ${ }^{(3)}$.

Parents, the main actors in child care, are the most affected with the diagnosis of a chronic disease. It is noteworthy that parents may exhibit physical and emotional symptoms such as loss of control, selfesteem, depression, anxiety, and present a higher risk of developing mental illness ${ }^{(4)}$. These reactions may be present in the relationship with the healthcare team and can interfere with parents' level of understanding, in adherence to treatment, and negatively influence the behavior of the child ${ }^{(5)}$.

In recent years, the health teams that care for a child with cancer have been encouraged to understand childhood cancer as a potentially stressful event for parents that can lead to emotional and psychological consequences during the treatment phase ${ }^{(6)}$ and also after its termination, even in cases in which the child was cured ${ }^{(7)}$. The focus of some research has been the evaluation of the impact of childhood cancer in the family(8-10), especially in the lives of parents, however these studies have presented controversial results: while some reported good adjustment ${ }^{(11-12)}$, others indicate high rates of parental stress ${ }^{(5,13)}$. For some researchers these discrepant findings may reflect, at least in part, the use of less sensitive methods to analyze the experiences of parents of children with chronic diseases ${ }^{(5)}$.

Considering that parents are the primary caregivers of children with chronic disease, this study aims to evaluate the level of stress of the parents of children with cancer, and to identify correlations with this sociodemographic data and anxiety levels.

\section{Method}

This was a descriptive, transversal study that was conducted at the Pediatric Clinic of the Hospital do Câncer A.C. Camargo (HACC) (São Paulo-SP) and the Associação dos Pais e Amigos da Criança com Câncer e Hemoglobinopatias (Association of Parents and Friends of Children with Cancer and Hemoglobinopathies) (APACC) (Campinas-SP). The population consisted of parents or guardians of children and adolescents with cancer. The accompanying parents or guardians, who had legal custody of the child, were considered for the sample. Included in the study were parents or guardians of children and adolescents aged between zero and 18 years, with a diagnosis of malignant neoplasm, in the treatment or monitoring phase. Those accompanying the children but who did not have legal custody, and those who for some reason showed exacerbated feelings of sadness, such as crying and other emotional reactions, were excluded, as this emotional mobilization could interfere with the judgment capacity of the parents in relation to the events evaluated by the instruments.

The sample $(n=101)$ was obtained by convenience and data collection was conducted during the period from 27 January to 15 June, 2009. In the hospital, we obtained the scheduling of children and after previous selection, considering the inclusion criteria, subjects were approached in the reception of the pediatric clinic before the medical consultation. In the outpatient support institution, we obtained the list of children and their companions and, after verification of the inclusion criteria, subjects were approached in the reception of the house of support. The instruments were completed during a single interview with the subjects, in a reserved location, and the time spent for each interview ranged between 13 and 72 minutes (mean=27.5 \pm 11.5 ).

Parents who agreed to participate were informed of the objectives of the study and signed the terms of free and informed consent. The study was approved by the Committee on Ethics in Research of the Hospital do Câncer A.C. Camargo (HACC), under Opinion n ${ }^{\circ} 1179 / 2008$, and the Faculty of Medical Sciences, University of Campinas (UNICAMP), under opinion $n^{\circ} 763 / 2008$.

The sociodemographic profile was obtained by a characteristics instrument composed of two parts, A) characteristics of the children: including data such as initials, date of birth, gender, date of diagnosis, diagnosis (according to the International Classification of Childhood Cancer) and if they were currently in treatment, and B) characteristics of the parents or guardians, such as family relationship with the child, date of birth, gender, marital status, number of children, employment status, family income, number of people living within this income, years of study, and origin. The sociodemographic data sheet was prepared by the researchers and subjected to content validity by a panel of judges, who evaluated the clarity and relevance of the content.

Two instruments were then administered: a specific scale for the evaluation of parental stress, called the 
Pediatric Inventory for Parents - PIP - Brazilian version (14), and a generic scale for the evaluation of anxiety - State-Trait Anxiety Inventory (STAI) ${ }^{(15-16)}$. To assess parental stress, the Pediatric Inventory for Parents - PIP - Brazilian version was used. The PIP - Brazilian version contains 42 items that assess the frequency and difficulty that the parents present in the face of events related to child care. These items are grouped into four domains: communication ( 9 items), emotional functioning (15 items), medical care ( 8 items) and role function (10 items), and are evaluated on two subscales: Frequency (PIP-F), those who experienced determined events in the past week and, Difficulty (D-PIP) in dealing with these situations ${ }^{(5,14)}$. The measurement scale was a Likert-type with five alternative responses, ranging from 1 point (not at all) to 5 points (extremely). The scores on the subscales are obtained separately for each of the two domains, and the sum of the scores for the domains composed the total score of each subscale, which can vary from 42 to 210 points, with higher scores indicating an elevated level of stress. The indices of reliability and validity of the PIP - Brazilian version were evaluated in other studies and presented satisfactory results(5,14,17-21).

The Inventário de Ansiedade Traço - Estado (IDATE), Brazilian version of the State-Trait Anxiety Inventory (STAI) has the aim of assessing two components of anxiety: state anxiety and trait anxiety. It is an instrument widely used in clinical practice and research to evaluate anxiety in adults ${ }^{(15)}$. To assess the presence of anxiety symptoms in parents, only the State-Anxiety Scale (STAI-S) was used, because it is considered sensitive to changes in tension, in accordance with the context, and that presents reliability indices ${ }^{(15-16)}$. The STAI-S contains 20 statements, in which subjects are guided to indicate how they feel in that moment, in relation to symptoms of anxiety. The measurement scale is of the Likert-type, with four points, where one means absolutely not, and four means exceedingly, for each of the items with statements about the current state of anxiety. The higher the score, the greater the anxiety ${ }^{(15)}$.

Data were organized using Microsoft ${ }^{\circledR}$ Office Excel 2007 and analyzed using the Statistical Analysis System (SAS - System for Windows ${ }^{\circledR}$ ), version 9.1.3 - 2002/2003. For characterization of the sample, descriptive and inferential analyses were used. The correlation between the scores of the PIP - Brazilian version and of the of the STAI-S with sociodemographic variables of the parents and children, and between scales were evaluated by means of the Spearman correlation coefficient ( $r$ ). The values of this coefficient indicate the degree of correlation and can range from -1 to +1 , where values between 0.30 and 0.50 indicate a moderate correlation and values above 0.50 indicate correlations of strong magnitude(22). The significance level adopted for the statistical tests was $5 \%(p<0.05)$.

\section{Results}

One hundred and one parents participated in the study, with a mean age of 36.0 years (SD \pm 7.8 ). The majority of respondents were from HACC (57.4\%); $94.1 \%$ were female, and $87.1 \%$ were mothers. Regarding education, the average years of education was 10.1 years $(\mathrm{SD} \pm 4.4, \min =2, \max =20$ years). The children whose parents were included in the study, were $51.5 \%$ male, aged between 8 months and 18 years, median 9.5 years $(\mathrm{SD} \pm 5.3)$, and $75.2 \%$ were under treatment at the time of the interview. The most common diagnoses were: acute lymphoblastic leukemia $(n=32)$, retinoblastoma $(n=10)$, and soft tissue sarcomas $(n=10)$. The mean time since diagnosis was 32.6 months ( $S D \pm 46.0$, $\min \leq 1$, $\max =196.8$ ), with prevalence in the age range of five to nine years (Table 1 ).

Table 1 - Sociodemographic characteristics of parents or guardians and children / adolescents with cancer. Campinas, SP, Brazil, 2009

\begin{tabular}{|c|c|}
\hline Variables & n (\%) \\
\hline \multicolumn{2}{|c|}{ Parents or Guardians } \\
\hline \multicolumn{2}{|l|}{ Gender } \\
\hline Female & $95(94.1 \%)$ \\
\hline Male & $6(5.9 \%)$ \\
\hline \multicolumn{2}{|l|}{ Kinship } \\
\hline Mother & $88(87.1 \%)$ \\
\hline Other & $13(12.9 \%)$ \\
\hline \multicolumn{2}{|l|}{ Marital status } \\
\hline Married & $70(69.3 \%)$ \\
\hline Stable union & $15(14.8 \%)$ \\
\hline Single & $9(8.9 \%)$ \\
\hline Separated & $4(4.0 \%)$ \\
\hline Widowed & $3(3.0 \%)$ \\
\hline \multicolumn{2}{|l|}{ Occupation } \\
\hline Paid activity & $35(34.7 \%)$ \\
\hline Unemployed & $26(25.7 \%)$ \\
\hline At home & $26(25.7 \%)$ \\
\hline Received benefits & $13(12.9 \%)$ \\
\hline Retired & $1(1.0 \%)$ \\
\hline \multicolumn{2}{|c|}{ Children } \\
\hline \multicolumn{2}{|l|}{ Gender } \\
\hline Male & $52(51.5 \%)$ \\
\hline Female & $49(48.5 \%)$ \\
\hline In Treatment & $76(75.2 \%)$ \\
\hline
\end{tabular}

(continue...) 
Table 1 - (continuation)

\begin{tabular}{lc}
\hline \multicolumn{2}{c}{ Children } \\
\hline Diagnosis \\
Leukemia & $32(31.7 \%)$ \\
Retinoblastoma & $10(9.9 \%)$ \\
Sarcomas & $10(9.9 \%)$ \\
Other & $49(48.5 \%)$ \\
\hline
\end{tabular}

Source: Alves, 2009

In this study, values of the scores ranged from 59 to 182 for subscale PIP-F, and from 49 to 188 for the PIP-D subscale. We obtained the mean score of 130.4 ( \pm 27.6 ) for the Frequency subscale, and 117.5 ( \pm 30.9) for the Difficulty subscale. The Emotional Functioning domain had the highest mean scores in both subscales $\left(M_{P I P-F}=\right.$ $47.9 \pm 11.4$ and $\left(M_{P I P-D}=48.5 \pm 12.9\right)$ (Table 2$)$.

Table 2 - Mean and standard deviations of the Pediatric Inventory for Parents - PIP - Brazilian version scores. Campinas, SP, Brazil, 2009

\begin{tabular}{lcccccc}
\hline \multirow{2}{*}{ Domains } & \multicolumn{2}{c}{ PIP - Frequency } & & \multicolumn{2}{c}{ PIP - Difficulty } \\
\cline { 2 - 3 } \cline { 6 - 7 } & $\mathbf{M}$ & SD $( \pm)$ & & $\mathbf{M}$ & SD $( \pm)$ \\
\hline Communication & 24.7 & 6.3 & & 21.4 & 6.7 \\
Medical Care & 28.2 & 6.4 & & 19.5 & 7.4 \\
Role Function & 29.6 & 7.5 & & 28.2 & 8.2 \\
Emotional Functioning & 47.9 & & 11.4 & & 48.5 & 12.9 \\
Total & 130.4 & 27.6 & & 117.5 & 30.9 \\
\hline
\end{tabular}

$\mathrm{SD}=$ standard deviation

Source: Alves, 2009

The three events with highest frequency for the subjects were: "Thinking about other children who have been seriously ill"; "Being with my child during medical procedures" and "Helping my child with his/her hygiene needs". Moreover, the three events with highest means on the Difficulty subscale were: "Feeling scared that my child could get very sick or die", "Worrying about the long term impact of the illness" and "Thinking about other children who have been seriously ill" (Table 3 ).

Table 3 - Items of Frequency and Difficulty scales of the PIP - Brazilian version with highest scores. Campinas, SP, Brazil, 2009

\begin{tabular}{lcccccc}
\hline \multirow{2}{*}{ PIP - Brazilian version } & \multicolumn{2}{c}{ Frequency } & & \multicolumn{2}{c}{ Difficulty } \\
\cline { 2 - 3 } \cline { 6 - 7 } & Mean & SD & & Mean & SD \\
\hline $\begin{array}{l}\text { Thinking about other children } \\
\text { who have been seriously ill }\end{array}$ & 4.17 & 0.94 & & 3.93 & 1.11 \\
$\begin{array}{l}\text { Being with my child during } \\
\text { medical procedures }\end{array}$ & 3.94 & 1.36 & & 2.62 & 1.56
\end{tabular}

(continue...)
Table 3 - (continuation)

\begin{tabular}{lllllll}
\hline \multirow{2}{*}{ PIP - Brazilian version } & \multicolumn{2}{c}{ Frequency } & & \multicolumn{2}{c}{ Difficulty } \\
\cline { 2 - 3 } \cline { 5 - 6 } & & Mean & SD & & Mean & SD \\
\hline $\begin{array}{l}\text { Helping my child with his/her } \\
\text { hygiene needs }\end{array}$ & 3.91 & 1.3 & & 1.78 & 1.18 \\
$\begin{array}{l}\text { Worrying about the long term } \\
\text { impact of the illness }\end{array}$ & 3.76 & 1.26 & & 3.56 & 1.33 \\
$\begin{array}{l}\text { Feeling scared that my child } \\
\text { could get very sick or die }\end{array}$ & 3.52 & 1.43 & & 3.98 & 1.44 \\
\hline
\end{tabular}

$\mathrm{SD}=$ standard deviation

Source: Alves, 2009

The scores of the PIP - Brazilian version showed no significant difference regarding gender of parents and children, marital status, income and years of education, but the age of the parents or guardians was significantly correlated in the Frequency subscale (PIP-F $r=-0.31$, $\mathrm{p}<0.01$; PIP-D $r=-0.18, \mathrm{p}=0.07)$, indicating that younger parents reported higher levels of stress than older parents. The age of the children was inversely correlated to the PIP-F scores $(r=-0.26 p=0.01)$, indicating that parents of younger children reported a higher frequency of stressful events. For both subscales, PIP-F and PIP-D, parents of children with shorter time since diagnosis had a higher frequency of and difficulty during stressful events (PIP-F $r=-0.25, p=0.01$; PIP$D r=-0.22, p=0.02$ ).

In the evaluation of anxiety, the scores ranged from 25 to 61 points, with a mean of $42.1( \pm 9.0)$. The STAI-E scores were inversely correlated with the child's age $(r$ $=-0.23 p=0.02)$, time since diagnosis $(r=-0.23 p=$ $0.02)$, treatment time $(r=-0.19 p=0.04)$, parental age $(r=-0.23 p=0.02)$ and family income $(r=-0.23$ $p=0.02$ ). Younger parents of younger children, with shorter time since diagnosis and treatment, and those with lower family incomes, were found to have more anxiety symptoms.

All areas of the PIP - Brazilian version resulted in significant positive correlation with state anxiety (Table 4). The emotional function domain showed a strong correlation with STAI-E (PIP- F Emotional Function $r=$ $+0.54, p<0.01$; PIP-D Emotional Function $r=+0.54, p$ $<0.01$, while other domains showed positive correlation of moderate magnitude, except in the communication domain, the Frequency subscale, which correlated positively with low magnitude (PIP-F Communication $r$ $=+0.28, \mathrm{p}<0.01)$. 
Table 4 - Spearman correlation coefficient between the scores PIP - Brazilian version of the STAI-S. Campinas, SP, Brazil, 2009

\begin{tabular}{lcc}
\hline \multicolumn{1}{c}{ PIP-Brazilian version } & STAI-S Correlation & $\mathbf{p}$ \\
\hline Frequency Subscale & & \\
Communication & +0.28 & 0.0051 \\
Medical Care & +0.36 & 0.0002 \\
Role Function & +0.42 & $<0.0001$ \\
Emotional Functioning & +0.54 & $<0.0001$ \\
Difficulty Subscale & & \\
Communication & +0.38 & $<0.0001$ \\
Medical Care & +0.35 & 0.0003 \\
Role Function & +0.36 & $<0.0001$ \\
Emotional Functioning & +0.54 & 0.0002 \\
\hline
\end{tabular}

Source: Alves, 2009

\section{Discussion}

The results of this study show that the profile of respondents was similar to studies involving caregivers and children with cancer, regarding the caregivers' mean age (36 years) ${ }^{(11)}$ and the mean age of the children (9.5 years $)^{(5,18)}$. The most frequent diagnosis among children was acute lymphoblastic leukemia, in agreement with the Brazilian statistics, followed by retinoblastoma, which contradicts national data in which the second most common neoplasm in children are lymphomas ${ }^{(1,23)}$. There was a slight male predominance among these children, which is also similar to what was encountered in these statistics ${ }^{(1,23)}$. The majority of the respondents were female, mothers, married or in stable relationships $(84.1 \%)$, who had an average of 10 years of study.

Our results show that mothers are the primary caregivers of the child, even when they have companions $^{(10)}$ and that $50 \%$ of caregivers have to rely on the income of other family members, since they do not have any kind of paid work activity. Some studies address that the diagnosis of childhood cancer requires the caregiver to leave employment because of an inability to reconcile the routine treatment of children with work, thus undermining the family income $e^{(9,10,24)}$. The family is also the primary source of emotional support for children and adolescents undergoing cancer treatment, which reinforces previous findings, in which adolescents relate family support as fundamental to coping with the disease, and that parents are responsible for the relief of suffering during procedures and hospital routines(2,25).

When sociodemographic variables were correlated with scores of the PIP-Brazilian version and the STAI-S, results showed that younger parents, and those of younger children, reported higher levels of stress and anxiety. These results suggest that the inexperience of those younger caregivers with the parental role can generate higher levels of stress and anxiety when they are faced with a child's chronic illness. As regards the age of the child, the higher level of stress exhibited by parents of younger children can be justified by their greater dependence in relation to self-care activities. However, these aspects need to be explored in future studies.

In relation to the time since diagnosis, parents of children with shorter time since diagnosis had a higher level of stress and anxiety. These data also been found in other studies in which parents had higher stress levels at the time of diagnosis, and then go through a period of adaptation to the disease, developing coping strategies ${ }^{(2,5,4,18)}$. However, some studies with parents of children who survived cancer, indicated that parents exhibited symptoms of stress and anxiety even after the child finished treatment, even in cases where the child was considered cured ${ }^{(11)}$. Parents reported intense preoccupation with the child, maintained vigilance with health issues and were constantly haunted by the fear of death and recidivism ${ }^{(2)}$.

The results of applying the PIP - Brazilian version confirmed considerations about the vulnerability of parents to symptoms of anxiety when faced with a disease condition of their children, especially the emotional function domain that obtained a strong positive correlation with the general measure of anxiety (STAI-S). Some research showed that there was a significant impairment of the emotional state of parents who faced cancer in their children. Emotional changes can result in illnesses such as depression and, thus, compromise the care that parents provide to their child, interfering with their social and family role, in their quality of life, and their relationship with the health team ${ }^{(11)}$.

It was possible to identify that the daily medical routines, fear of the death of a child, the sequel of disease, and care of the sick child can affect the wellbeing of the parents ${ }^{(5,17-21,26-27)}$. The positive correlations between the PIP-Brazilian version and STAI-S indicated that the higher the stress level of parents, the more anxiety symptoms they exhibited, which can be seen in other studies of children with cancer $^{(5,18)}$ and, also, in studies involving other chronic conditions in children, such as hemophilia(19,26).

\section{Conclusion}

The research investigating the psychosocial factors associated with the experience of pediatric cancer, 
especially with regard to the impact of chronic illness on the lives of parents, can help with the proper care for the family. In this sense, the use of instruments that measure stress and anxiety of parents can provide information with respect to the adaptation to the chronic illness, and about the situations related to the disease that cause more suffering for parents. In Brazil, the lack of specific tools for this type of evaluation is a challenge for Brazilian researchers.

The study aimed to evaluate the stress and anxiety in parents of children with cancer through the use of instruments. Future studies about the emotional changes experienced by parents should also include aspects such as the occurrence of mental illness and continuous use of medication.

The suffering of parents of children with a chronic illness results in high levels of stress and the occurrence of symptoms of anxiety. In clinical practice, the fragility of this situation may compromise the understanding, on the part of parents, of the care needs of the child and the relationship with the healthcare team. The results of this study indicate for the nurse that these situations are more stressful for parents of children with cancer and suggest that the planning of nursing care includes the family in decisions about their care. Most parents want to be beside the child during painful procedures, and feel more confident when they help their children cope with the illness and hospitalization process.

On the other hand, some parents show high levels of stress and cannot feel sufficiently secure to trust the care provided by nursing and healthcare staff. It is in this scenario that nurses should use their expertise to help parents manage their stress levels, to establish a relationship of trust, in which assertive communication and understanding of the suffering make the nurse the person on whom parents can count during difficult times.

\section{References}

1. Instituto Nacional do Câncer (INCA). Coordenação de prevenção e vigilância de câncer. Câncer da criança e adolescente no Brasil: dados dos registros de base populacional e de mortalidade. Rio de Janeiro: INCA; 2008.

2. Cicogna EC, Nascimento LC, Lima RAG. Crianças e adolescentes com câncer: experiências com a quimioterapia. Rev. Latino-Am. Enfermagem. 2010;18: 864-72.

3. Menezes CNB, Passareli PM, Drude FS, Santos MA, Valle ERM. Câncer infantil: organização familiar e doença. Rev Mal-Estar Subjetividade 2007;7:191-210.
4. Norberg AL. Pöder U, Ljungman G, von Essen L. Objective and subjective factors as predictors of posttraumatic stress symptoms in parents of children with cancer - a longitudinal study. Plos One. 2012;7(5):1-7.

5. Streisand R, Braniecki S, Tercyak KP, Kazak AE. Childhood illness-related parenting stress: the pediatric inventory for parents. J Pediatr Psychol. 2001 Apr;26(3):155-62.

6. Kazak AE, Boeving CA, Alderfer MA, Hwang WT, Reilly A. Posttraumatic stress symptoms during treatment in parents of children with cancer. J Clin Oncol. 2005 Oct 20;23(30):7405-10.

7. Kazak AE, Alderfer M, Rourke MT, Simms S, Streisand R, Grossman JR. Posttraumatic stress disorder (PTSD) and posttraumatic stress symptoms (PTSS) in families of adolescent childhood cancer survivors. J Pediatr Psychol. 2004 Apr;29(3):211-9.

8. Del Bianco Faria AM, Cardoso CL. Aspectos Psicossociais de acompanhantes cuidadores de crianças com câncer: stress e enfrentamento. Estudos Psicol. 2010;27(1):13-20.

9. Ortiz MCA, Lima RAG. Experiências de familiares de crianças e adolescentes, após o término do tratamento contra o câncer: subsídios para o cuidado de enfermagem. Rev. Latino-Am. Enfermagem. 2007;15(3):411-7.

10. Santo EARE, Gaiva MAM, Espinosa MM, Barbosa DA, Belasco AGS. Cuidando da criança com câncer: avaliação da sobrecarga e qualidade de vida dos cuidadores. Rev. Latino-Am. Enfermagem. 2011;19(3):1-9.

11. Kazak $A E$, Cant $M C$, Jensen $M M$, McSherry $M$, Rourke MT, Hwang WT, et al. Identifying psychosocial risk indicative of subsequent resource use in families of newly diagnosed pediatric oncology patients. J Clin Oncol. 2003 Sep 1;21(17):3220-5.

12. Frank NC, Brown RT, Blount RL, Bunke V. Predictors of affective responses of mothers and fathers of children with cancer. Psychooncology. 2001 Jul;10(4):293-304.

13. Rodriguez EM, Dunn MJ, Zuckerman T, Vannatta K, Gerhardt CA, Compas BE. Cancer-related sources of stress for children with cancer and their parents. J Pediatr Psychol.2012;37(2):185-97.

14. Alves DFS. Adaptação e validação do instrumento Pediatric Inventory for Parents - PIP para a cultura brasileira. [Dissertação de Mestrado]. Campinas: Faculdade de Ciências Médicas da Universidade Estadual de Campinas; 2009.

15. Andrade L, Gorenstein C, Vieira Filho AH, Tung TC, Artes R. Psychometric properties of the Portuguese version of the State-Trait Anxiety Inventory applied to college students: factor analysis and relation to 
the Beck Depression Inventory. Braz J Med Biol Res. 2001;(34):367-74.

16. Barnes LLB, Harp D, Jung WS. Reliability Generalization of Scores on the Spielberger StateTrait Anxiety Inventory. Educ Psychol Measure. 2002;(62):603-18.

17. Preston A, Storch EA, Lewin A, Geffken GR, Baumeister $A L$, Strawser $M S$, et al. Parental stress and maladjustment in children with short stature. Clin Pediatr. 2005 May;44(4):327-31.

18. Vrijmoet-Wiersma CM, Hoekstra-Weebers JE, Margreet de Peinder WM, Koopman HM, Tissing WJ, Treffers PD, et al. Psychometric qualities of the Dutch version of the Pediatric Inventory for Parents (PIP): a multi-center study. Psychooncology. 2010 Apr;19(4):368-75.

19. Rincon C, Remor E, Arranz Pr. Estudio psicométrico preliminar de la versión española el Pediatric Inventory for Parents (PIP). Int J Clin Health Psychol. 2007; (7):43552.

20. Farley LM, DeMaso DR, D'Angelo E, Kinnamon C, Bastardi $\mathrm{H}$, Hill CE, et al. Parenting stress and parental post-traumatic stress disorder in families after pediatric heart transplantation. J Heart Lung Transplant. 2007 Feb;26(2):120-6.

21. Streisand R, Swift E, Wickmark T, Chen R, Holmes CS. Pediatric parenting stress among parents of children with type 1 diabetes: the role of self-efficacy, responsibility, and fear. J Pediatr Psychol. 2005 Sep;30(6):513-21.

22. Hulley SB, Cummings SR, Browner WS, Grady D, Hearst N, Newman TB. Delineando a pesquisa clínica: uma abordagem epidemiológica. 2a ed. Porto Alegre: Editora Artmed; 2003.

23. Reis RS, Santos MO, Thuler LCS. Incidência de tumores pediátricos no Brasil. Rev Bras Cancerol. 2007;53(1):5-15.

24. Beck ARM, Lopes MHB. Tensão devido ao papel de cuidador entre cuidadores de criança com câncer. Rev Bras Enferm.2007;60(5):513-8.

25. Lombardo MS, Popim RC, Suman AL. Da onipotência ao desgaste: as perspectivas do adolescente em quimioterapia. Rev. Latino-Am. Enfermagem. 2011;19(3):531-9.

26. Mensorio MS, Kohlsdorf M, Costa Junior AL. Cuidadores de crianças e adolescentes com leucemia: análise de estratégias de enfrentamento. Psicol Rev. 2009;158-76.
27. Menossi MJ, Zorzo JCC, Lima RAG. A dialógica vida/ morte no cuidado do adolescente. Rev. Latino-Am. Enfermagem. 2012;20:126-34. 